\title{
Multivariate analysis on blackgram genotypes for bruchine (Callosobruchus maculatus F.) resistance towards selection of parental lines
}

\author{
Ragul Subramaniyan \\ National Pulses Research Centre, Tamil Nadu Agricultural University, Vamban - 622303 \\ (Tamil Nadu), India \\ Manivannan Narayana * \\ Centre for Plant Breeding and Genetics, Tamil Nadu Agricultural University, Coimbatore \\ - 641003 (Tamil Nadu), India

\section{lyanar Krishnamoorthy} \\ Department of Millets, Tamil Nadu Agricultural University, Coimbatore - 641003 (Tamil Nadu), \\ India \\ Ganapathy Natarajan \\ Department of Agricultural Entomology, Tamil Nadu Agricultural University, Coimbatore \\ - 641003 (Tamil Nadu), India \\ Karthikeyan Gandhi \\ Department of Plant Pathology, Tamil Nadu Agricultural University, Coimbatore - 641003 \\ (Tamil Nadu), India \\ *Corresponding author. Email: nm68@tnau.ac.in
}

\section{Article Info}

https://doi.org/10.31018/

jans.v13i4.2997

Received: September 4, 2021

Revised: October 23, 2021

Accepted: October 27, 2021

\section{How to Cite}

Subramaniyan, R. et al. (2021). Multivariate analysis on blackgram genotypes for bruchin (Callosobruchus maculatus (F.)) resistance towards selection of parental lines. Journal of Applied and Natural Science, 13(4), 1206 - 1213. https://doi.org/10.31018/ jans.v13i4.2997

\begin{abstract}
Black gram (Vigna mungo (L.) Hepper) is one of the most important pulse crops in daily diets. However, black gram production and post-harvest preservation are still tedious due to the losses caused by the storage pest bruchine, Callosobruchus maculatus (F.), both quantitatively and qualitatively. Hence, the present study involves the utilization of the multivariate analysis by effectively understanding variation among the genotypes based on their level of bruchine infestation. The multivariate studies indicated that the traits viz., the total number of adult emergence (AE), seed damage \% (SD) and seed weight loss \% (SWL) had more variation and with more significant correlation among them. Also, these traits are the most influential principal component traits governing $88 \%$ of the variation among genotypes. The divergence analysis showed that the genotype TU 68 found in cluster II would have the potential to create the variation for bruchine infestation among the black gram genotypes involved in the study. As it has scored lesser adult emergence (AE) (7 adults), seed damage \% (SD) (14\%) and seed weight loss \% (SWL) $(17.79 \%)$ than the other genotypes. It shows the resistant nature of the genotype against bruchine beetles. Hence, TU 68 could be utilized in the future hybridization programme as a donor for bruchine resistance.
\end{abstract}

Keywords: Association, Blackgram, Bruchine, Cluster, PCA, Resistance

\section{INTRODUCTION}

Blackgram [Vigna mungo (L.) Hepper] is one of the important pulse crops of India. India is the largest producer and also consumer of blackgram. It is referred to as the "king of the pulses" due to its delicious taste and numerous other nutritional qualities. It is also popular for its fermented foods in Southern India. In India, the area that comes under blackgram is about 4.50 million hectares with a production of 2.83 million tonnes (Anonymous, 2019). Among various biotic and abiotic yield limiting factors, storage pests that feed on seeds have always been one of the most important biotic constraints for the crop and cause severe economic loss during post-harvest storage. The net quantum of productivity and its economic value is constantly being affected by the storage pests, especially the storage pest bruchine (Callosobruchus sp.) (Swella and Mushobozy, 2009). Bruchine infestation primarily starts in the field condition and carry over into the storage condition where the seeds are completely damaged within 2-3 months. Damaged seeds lose their seed weight as well 
as their nutritional quality. So, the post-harvest losses are the major obstacles to fulfil food security in developing nations (Somta et al., 2007; Ponnusamy et al., 2014). The post-harvest damage caused by the bruchine beetles varies from crop to crop, depending on the prevalent species and their respective biotype. In India, C. maculatus is responsible for $90 \%$ yield loss in black gram (Soundararajan et al., 2013). Hence, a study was undertaken to identify the resistant nature of 20 blackgram cultivars towards the infestation by $C$. maculatus. Principle component analysis (PCA) mainly emphasizes phenotypic traits components and their association by understanding the distribution among correlated and uncorrelated traits for the given phenotypes. Genetic diversity is an evolutionary platform where the created groups transfer the desirable genes through the hybridization process from the parent to progeny (Sharifi et al., 2018; Perera et al., 2017). The success of any breeding program depends on the magnitude of genetic variability and the extent of association between traits. Hence, the present study aimed at identifying the diverse set of parents through multivariate analysis among the blackgram genotypes against bruchine infestation.

\section{MATERIALS AND METHODS}

\section{Source of seeds and insect culture}

The seeds of twenty blackgram genotypes were obtained from the National Pulses Research Center (NPRC), Vamban, India and Bhabha Atomic Research Center, Trombay, India. Adults of C. maculatus were initially collected from infested seed lots from NPRC, Vamban. Among the various species, C. maculatus covers the major proportion of nearly $90 \%$ in the seed lots of Vamban. A representative sample of $C$. maculutus was collected and maintained on greengram [Vigna radiata (L.) Wilczek] seeds with temperature ranging of $29^{\circ}-32^{\circ} \mathrm{C}$ and $60-70 \% \mathrm{RH}$ for multiplication.

\section{Experimental design}

The experimental design for this study was a completely randomized design under three replicates per entry. The bruchine screening experiment was carried out at Entomology laboratory at NPRC, Tamil Nadu Agricultural University, Vamban. The assay procedure of Dongre et al. ( 1996) was followed with some modifications. Modification such as instead of two pairs of adults, five pairs of adults were released on 50 seeds of each genotype with replication placed in a $15 \mathrm{~cm}$ diameter plastic Petri plates. The insects were allowed to remain in petriplates for five days for oviposition. After five days the adults were removed from petriplates.

\section{Data observation for evaluation of bruchine infestation}

Observations were recorded on oviposition on 50 seeds, the mean number of eggs per seed, developmental time (egg + larval + pupal stages) (days), adult emergence, mean developmental period (days), Howe's Index of susceptibility, seed damage (\%) and seed weight loss (\%). Seed damage and seed weight loss were estimated 50 days after adult infestation (DAI). The adults who emerged were counted on a daily basis and removed from the petriplates to avoid secondary infestation.

\section{Statistical analysis}

The data was analyzed by a completely randomized design. The descriptive statistics including range, mean, standard error and the principal component analysis (PCA) was done by the method described by Upadhyaya et al. (2002). The clustering was performed using Tocher's method. The multivariate analysis was performed using software PYTHON programming language. Variability parameters like phenotypic coefficient of variation (PCV), genotypic coefficient of variation (GCV), heritability $\left(\mathrm{h}^{2}\right)$ and genetic advance as per cent of mean (GAM) were calculated as suggested by Johnson et al. 1955. The data were analyzed using the statistical software TNAUSTAT statistical package (Manivannan, 2014).

\section{RESULTS AND DISCUSSION}

The multivariate analysis is known to be good at evaluating the genotypes by identifying the potential traits that should be further evaluated at the genetic level (Mohammad et al., 2009). Multivariate analysis is the best tool for choosing promising genotypes for the breeding programme (Ceolin et al. 2007). The basic pre -requisite thing in the multivariate analysis and the divergence analysis is the presence of significant differences among the genotypes taken for study. The Analysis of variance (ANOVA) of the present data revealed significant differences among the genotypes for all traits of bruchine infestation involved in multivariate analysis.

The descriptive data of bruchine resistance traits of 20 blackgram genotypes from three replications are furnished in Table. 1. The traits number of eggs per 50 seeds ranged from (48 - 147). The mean eggs per seed ranged from $1-2.9$ ensures the presence of at least one egg per seed through the artificial screening method. The developmental time among the screened genotypes ranging from 21 - 39 days showed that the prevalence of the prolonged developmental time i.e., delayed emergence. Regarding the trait total number of adult emergence $(6-50)$, the range indicated that the pres- 
Table 1. Descriptive statistics of bruchine resistant traits on blackgram genotypes

\begin{tabular}{|c|c|c|c|c|c|}
\hline \multirow{2}{*}{$\frac{\text { S. No. }}{1}$} & \multirow{2}{*}{$\begin{array}{l}\text { Traits observed } \\
\text { Number of eggs/50 seeds (NES) }\end{array}$} & \multicolumn{2}{|c|}{ Mean \pm Standard Error } & \multirow{2}{*}{$\frac{\text { Min }}{48.0}$} & \multirow{2}{*}{$\frac{\operatorname{Max}}{147.0}$} \\
\hline & & $77.63 \pm$ & 2.59 & & \\
\hline 2 & Mean No. of eggs/seed (MNES) & $1.55 \pm$ & 0.05 & 1.0 & 2.9 \\
\hline 3 & Developmental time (days) (D.T) & $26.18 \pm$ & 0.43 & 21.0 & 39.0 \\
\hline 4 & Total No. of Adult emergence (A.E) & $35.62 \pm$ & 1.40 & 6.0 & 50.0 \\
\hline 5 & Mean developmental period (days) (MDP) & $32.78 \pm$ & 0.48 & 26.9 & 44.2 \\
\hline 6 & Index of susceptibility (I.S) & $9.45 \pm$ & 0.22 & 3.5 & 12.4 \\
\hline 7 & Seed damage (\%) (SD) & $71.00 \pm$ & 2.76 & 12.0 & 98.0 \\
\hline 8 & Seed weight loss (\%) (SWL) & $34.37 \pm$ & 1.08 & 14.5 & 50.0 \\
\hline
\end{tabular}

ence of contrasting genotypes for the bruchine resistance among the screened genotypes. The mean developmental period ranged from 26.9 - 44.2 days after infestation, the index of susceptibility ranged from 3.5 - 12.4, the seed damage percentage and seed weight loss percentage ranged from 12.0 - 98.0 and 14.5 - 50.0, respectively. The descriptive statistics based on the bruchine resistance traits indicated that the presence of diverse range genotypes in the study. The principal component analysis (PCA) showed that PC1 and PC2 alone accounted for $88 \%$ of the cumulative proportion of variation (Table 2). The Eigen values of the principal components PC1 and PC2 were found to be greater than unity (one) were shown in the Scree plot (Fig. 1). In PC1, all traits were positively contributed with $63 \%$ of variation except traits viz., development time and mean developmental period. Among them, more positive contribution was rendered by the index of susceptibility $(0.41)$, the total number of adult emergence (0.41), seed damage (0.41) and seed weight loss (0.39). While rest of the components, viz., number of eggs per 50 seeds (0.57), the mean number of eggs per seed (0.58), mean developmental period (0.42) and

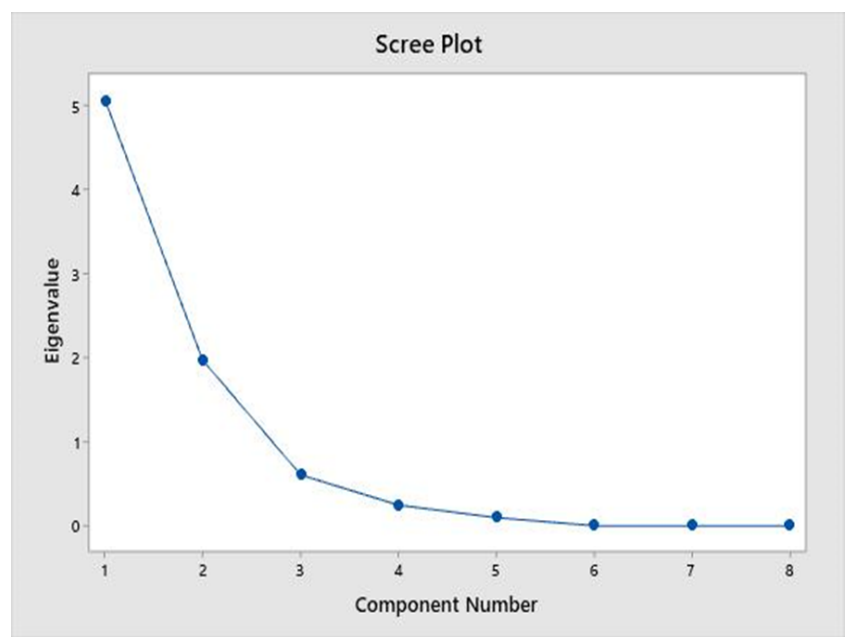

Fig. 1. Scree plot for the Eigen values of the principal components on bruchid infestation. developmental time (0.30) were positively contributed more variation in PC2 (Table. 2) (Fig. 2). Hence, the foremost importance has to be given to those traits with more contribution towards variation for the selection of parental lines for bruchine resistance. It will help to select bruchine resistant donor for future hybridization program.

The genetic divergence study grouped the 20 blackgram genotypes into four clusters based on Tocher's method (Table 3). The dendrogram heat map is furbished in Fig. 3. The results are in agreement with Ghosh et al. 2019. Among the clusters, cluster I was the major one with nine genotypes, followed by cluster III and cluster IV with eight and two genotypes, respectively. Cluster II was found solitary with only one genotype. The intra and inter cluster distance among the clusters is furnished in Table 4 . The maximum intra cluster distance was shown by cluster I (12.7), followed by cluster III (12.2) and cluster IV (12.2). This maximum intra-cluster distance indicated that the genotypes present within these clusters were more diverse than the other clusters. Comparing intra and inter-cluster distance, inter-cluster distance will be helpful in the

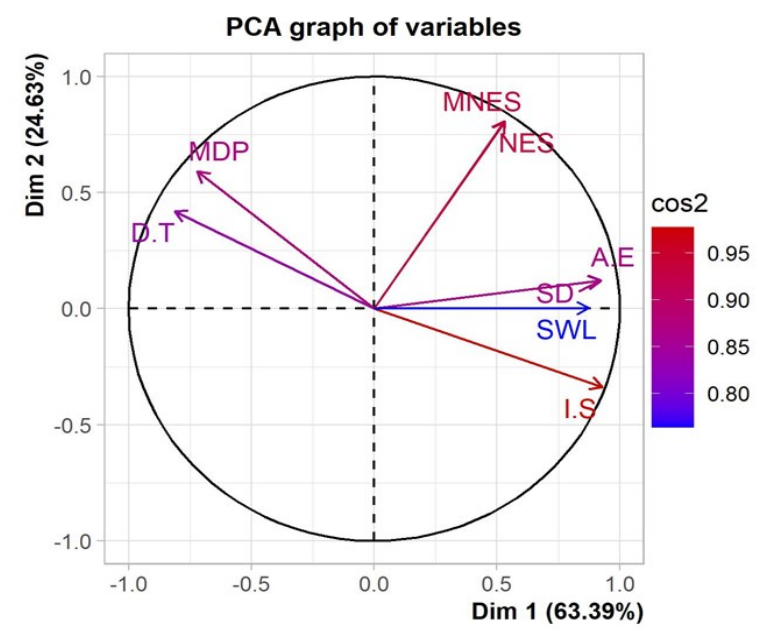

Fig. 2. Biplot on various bruchine resistance trait on blackgram genotypes 
Table 2. Principal components of bruchine resistant traits on blackgram genotypes

\begin{tabular}{|c|c|c|c|c|c|c|c|c|c|}
\hline S. No. & Traits observed & PC1 & PC2 & PC3 & PC4 & PC5 & PC6 & PC7 & PC8 \\
\hline 1 & Number of eggs/50 seeds (NES) & 0.24 & 0.57 & 0.33 & 0.00 & 0.06 & -0.03 & -0.03 & -0.71 \\
\hline 2 & Mean No. of eggs/seed (MNES) & 0.24 & 0.58 & 0.33 & 0.01 & 0.06 & 0.03 & 0.03 & 0.71 \\
\hline 3 & Developmental time (days) (DT) & -0.36 & 0.30 & -0.41 & 0.14 & 0.77 & -0.03 & -0.01 & 0.00 \\
\hline 4 & Total No. of Adult emergence (AE) & 0.41 & 0.09 & -0.43 & 0.30 & -0.11 & 0.12 & 0.73 & -0.04 \\
\hline 5 & Mean developmental period (days) (MDP) & -0.32 & 0.42 & -0.40 & -0.12 & -0.52 & -0.52 & -0.05 & 0.03 \\
\hline 6 & Index of susceptibility (IS) & 0.41 & -0.24 & 0.07 & 0.21 & 0.26 & -0.81 & -0.08 & 0.03 \\
\hline 7 & Seed damage (\%) (SD) & 0.41 & 0.09 & -0.43 & 0.32 & -0.13 & 0.26 & -0.68 & 0.02 \\
\hline 8 & Seed weight loss (\%) (SWL) & 0.39 & 0.00 & -0.29 & -0.86 & 0.19 & 0.01 & -0.01 & 0.01 \\
\hline \multicolumn{2}{|c|}{ Eigen Values } & 5.07 & 1.97 & 0.61 & 0.25 & 0.10 & 0.00 & 0.00 & 0.00 \\
\hline \multicolumn{2}{|c|}{ Proportion of Variance } & 0.63 & 0.25 & 0.08 & 0.03 & 0.01 & 0.00 & 0.00 & 0.00 \\
\hline \multicolumn{2}{|c|}{ Cumulative Proportion } & 0.63 & 0.88 & 0.96 & 0.99 & 1.00 & 1.00 & 1.00 & 1.00 \\
\hline
\end{tabular}

Table 3. Clustering pattern among blackgram genotypes

\begin{tabular}{lll}
\hline Cluster number & $\begin{array}{l}\text { Number of } \\
\text { genotypes }\end{array}$ & Constituent genotypes \\
\hline I & 9 & $\begin{array}{l}\text { APK 1, KKM 1, MASH 1008, CO 6, MDU 1, LBG 752, VBN(Bg)7, ADT 6, } \\
\text { VBN 11 }\end{array}$ \\
II & 1 & TU 68 \\
III & 8 & TMV 1, CO 5, VBN(Bg)4, ADT 3, VBN 6, VBN 9, LBG 787, VBN 8 \\
IV & 2 & ADT 5, MASH114 \\
\hline
\end{tabular}

Table 4. Average intra (bold) and inter cluster distances in blackgram genotypes

\begin{tabular}{lllll}
\hline & Cluster I & Cluster II & Cluster III & Cluster IV \\
\hline Cluster I & 12.7 & & & \\
Cluster II & 92.7 & 0.0 & & \\
Cluster III & 40.0 & 57.6 & 12.2 & 12.2 \\
Cluster IV & 36.6 & 64.9 & 33.0 & \\
\hline
\end{tabular}

identification of the genetic divergence among the genotypes of the experimental material (Reddy et al., 2018). Maximum inter-cluster distance (92.7) was observed between cluster II and I followed by cluster IV and II (64.9) and cluster III and II (57.6). Inter cluster distances and mean values of clusters (Table. 5) indicated that cluster II (TU 68) found to be a potential donor as it showed the superior nature of bruchine resistance. It had superior performance on bruchine resistance traits viz., number of eggs laid per 50 seeds (NES), the mean number of eggs per seed (MNES), developmental time (DT), adult emergence at 50 days after infestation (AE), mean developmental period (MDP) and less susceptibility index (IS). And also, it recorded less seed damage \% (SD) and seed weight loss \% (SWL). The principal component traits also clearly showed the genotype's superiority in cluster III (TU 68) for bruchine resistance among the genotypes. The genotype TU 68 confirmed its resistance in another study reported by Swamy et al., 2016. Hence, this genotype TU 68 is confirmed for bruchine resistance and can be involved in further bruchine resistance breeding programme.

The variability parameters such as phenotypic coefficient of variation (PCV), genotypic coefficient of variation (GCV), heritability $\left(\mathrm{h}^{2}\right)$ and genetic advance as per cent of mean (GAM) are presented in Table. 6. Among traits taken for the study, PCV was found to be slightly greater than the GCV, which showed less prevalence of environmental influence among the bruchine resistance traits. High PCV was recorded for the traits total number of adult emergence (AE) $(30.91 \%)$ followed by seed damage \% (SD) $(30.63 \%)$, the mean number of eggs per seed (MNES) (26.03\%), number of eggs per 50 seeds (NES) $(26.02 \%)$ and seed weight loss \% (SWL) $(24.67 \%)$. The remaining traits recorded moderate PCV. High GCV was recorded by the traits total number of adult emergence (AE) (28.22\%) followed by seed damage \% (SD) (28.06\%) and seed weight loss \% (SWL) $(20.08 \%)$. In comparison, all other traits recorded moderate GCV. High PCV and GCV indicated the presence of greater genetic variability for these bruchine resistance traits among the genotypes.

High heritability $\left(\mathrm{h}^{2}\right)$ was recorded for all traits, except 
Table 5. Cluster mean values for four clusters obtained by Tocher's method

\begin{tabular}{lllllllll}
\hline & NES & MNES & DT & AE & MDP & IS & SD & SWL \\
\hline Cluster I & 87.78 & 1.76 & 25.48 & 44.70 & 32.29 & 10.29 & 88.89 & 39.32 \\
Cluster II & 60.00 & 1.20 & 38.00 & 7.00 & 43.47 & 3.88 & 14.00 & 17.79 \\
Cluster III & 63.71 & 1.27 & 25.46 & 30.63 & 31.90 & 9.36 & 61.25 & 31.55 \\
Cluster IV & 96.50 & 1.93 & 26.34 & 29.00 & 33.15 & 8.82 & 58.00 & 31.72 \\
\hline
\end{tabular}

NES- Number of eggs/50 seeds, MNES - Mean No. of eggs/seed, DT- Developmental time (days), AE- Total No. of Adult emergence, MDP- Mean developmental period (days), IS- Index of susceptibility, SD- Seed damage (\%), SWL- Seed weight loss (\%)

Table. 6: Variability analysis on various bruchine resistant traits on blackgram genotypes

\begin{tabular}{llllll}
\hline S. No. & Traits observed & PCV (\%) & GCV (\%) & $\mathbf{h}^{\mathbf{2}}$ (\%) & GAM (\%) \\
\hline 1 & Number of eggs/50 seeds (NES) & 26.02 & 18.33 & 49.62 & 26.60 \\
2 & Mean No. of eggs/seed (MNES) & 26.03 & 18.33 & 49.62 & 26.60 \\
3 & Developmental time (days) (DT) & 13.00 & 12.66 & 94.82 & 25.39 \\
4 & Total No. of Adult emergence (AE) & 30.91 & 28.22 & 83.37 & 53.08 \\
5 & Mean developmental period (days) (MDP) & 11.50 & 10.29 & 80.03 & 18.96 \\
6 & Index of susceptibility (IS) & 18.46 & 17.13 & 86.05 & 32.73 \\
7 & Seed damage (\%) (SD) & 30.63 & 28.06 & 83.89 & 52.94 \\
\hline
\end{tabular}

Table 7. Correlation analysis on various bruchine resistant traits on blackgram genotypes

\begin{tabular}{|c|c|c|c|c|c|c|c|c|}
\hline & NES & MNES & DT & $\mathrm{AE}$ & MDP & IS & SD & SWL \\
\hline NES & 1.00 & & & & & & & \\
\hline MNES & 1.00 & 1.00 & & & & & & \\
\hline DT & -0.17 & -0.17 & 1.00 & & & & & \\
\hline$A E$ & $0.50^{*}$ & $0.50^{*}$ & $-0.59^{\star}$ & 1.00 & & & & \\
\hline MDP & 0.01 & 0.01 & $0.89^{*}$ & $-0.49^{*}$ & 1.00 & & & \\
\hline IS & 0.24 & 0.24 & $-0.89^{*}$ & $0.81^{*}$ & $-0.90^{*}$ & 1.00 & & \\
\hline SD & $0.50^{*}$ & $0.50^{*}$ & $-0.59^{*}$ & $1.00^{*}$ & $-0.49^{*}$ & $0.81^{*}$ & 1.00 & \\
\hline SWL & 0.41 & 0.41 & $-0.65^{*}$ & $0.82^{*}$ & $-0.54^{*}$ & $0.76^{*}$ & $0.81^{*}$ & 1.00 \\
\hline
\end{tabular}

${ }^{*}$ significant at $5 \%$ probability, NES- Number of eggs/50 seeds, MNES - Mean No. of eggs/seed, DT- Developmental time (days), AETotal No. of Adult emergence, MDP- Mean developmental period (days), IS- Index of susceptibility, SD- Seed damage (\%), SWL- Seed weight loss (\%)

the number of eggs per 50 seeds (NES) and mean the number of eggs per seed (MNES), which showed moderate heritability. Hence traits with high heritable nature can be subjected to selection for further trait improvement. High Genetic advance as per cent of mean (GAM) was recorded for all traits except mean developmental period (MDP) which showed moderate genetic advance as per cent of mean (GAM). Hence the selection for the bruchine resistance traits with high heritability and high genetic advance as per cent of mean is recommended for the genetic improvement program. Among the traits viz., total number of adult emergence $(A E)$, seed damage \% (SD) and seed weight loss \%
(SWL) indicated the presence of more variability among them. Similar type of results also reported by Indhu et al., 2018 in screening other set of blackgram genotypes for bruchine resistance. Hence selection based on these traits can be utilized for crop improvement program.

The estimate of correlation coefficients for the bruchine resistant traits are presented in the Table 7 . The Correlogram heat map on bruchine resistance traits is furbished in Fig. 4. It indicates the trait seed weight loss had a significant positive association with total number of adult emergence (0.82), seed damage \% (0.81) and index of susceptibility (0.76). However, the trait seed 


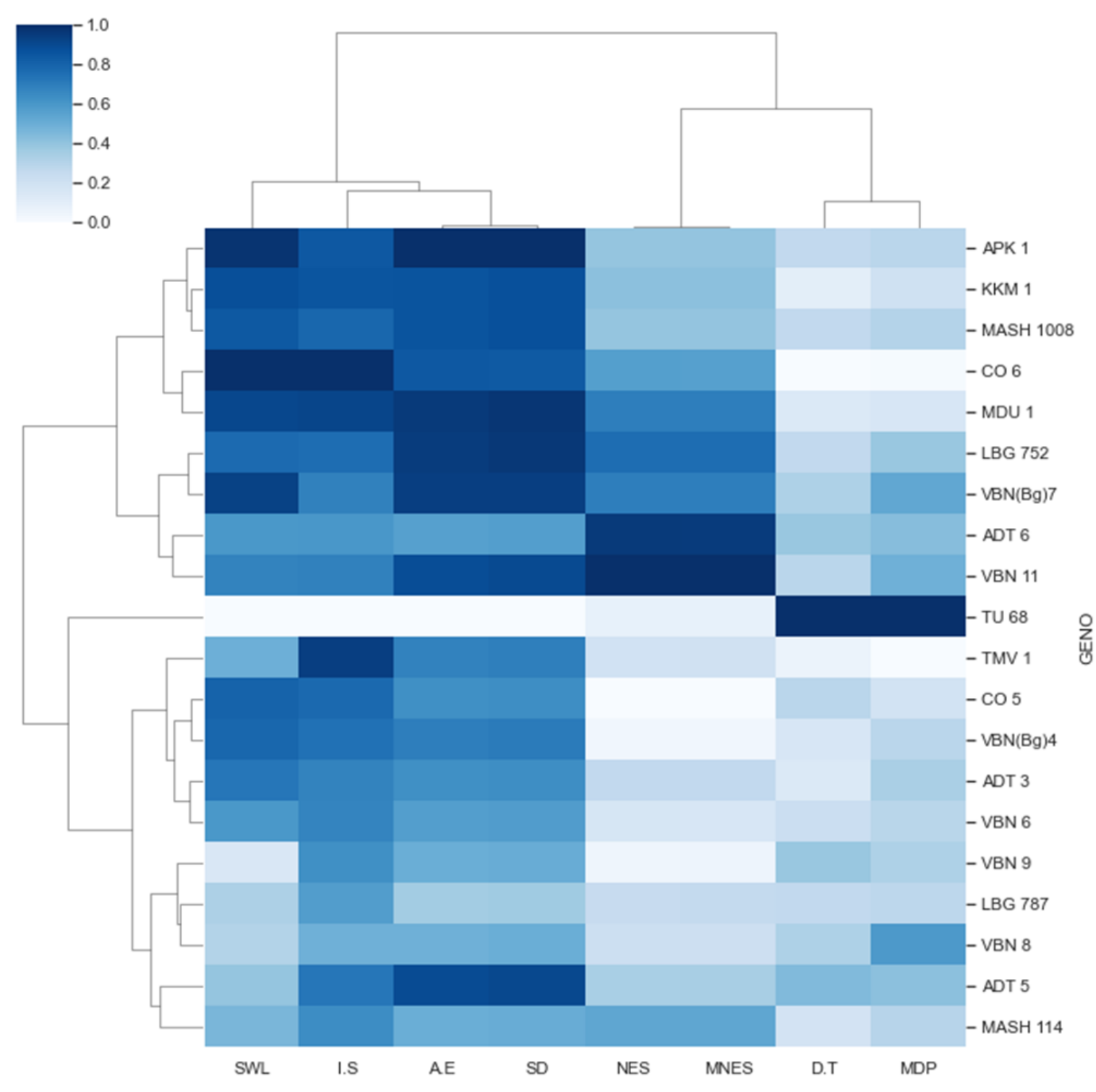

$\mathrm{Y}$-axis $=$ Genotypes $; \mathrm{X}$ - axis $=$ Bruchine resistance traits.

Fig. 3. Dendrogram heat map on various bruchine resistance traits on blackgram genotypes

weight loss percentage had recorded significant and negative association with developmental time $(-0.65)$ and mean developmental period (-0.54). This indicates that the trait seed weight loss decreases with increasing developmental time and mean developmental period. The trait seed damage showed a significant and positive association with a total number of adult emergence (1.00), index of susceptibility (0.81), the number of eggs per 50 seeds (0.50) and mean number of eggs per seed (0.50). However, the trait seed damage had recorded a negative and significant association with developmental time (-0.59) and mean developmental period (-0.49). Index of susceptibility had a significant positive association with a total number of adult emergence (0.81). It also recorded a significant and negative association with developmental time $(-0.89)$ and mean developmental period (-0.90). The trait mean develop- mental period had a significant positive association with developmental time (0.86). Total number of adult emergence had significant positive association with the number of eggs per 50 seeds (0.41) and mean number of eggs per seed (0.41). It also recorded a negative and significant association with developmental time (-0.59). Hence these correlated traits can be directly involved in the genetic improvement program.

\section{Conclusion}

The present investigation on the identification of potential donors for bruchine infestation and in the framing of the hybridization programme based on the multivariate analysis indicated that the traits viz., total number of adult emergence (AE), seed damage \% (SD) and seed weight loss \% (SWL) had more variations in black gram 


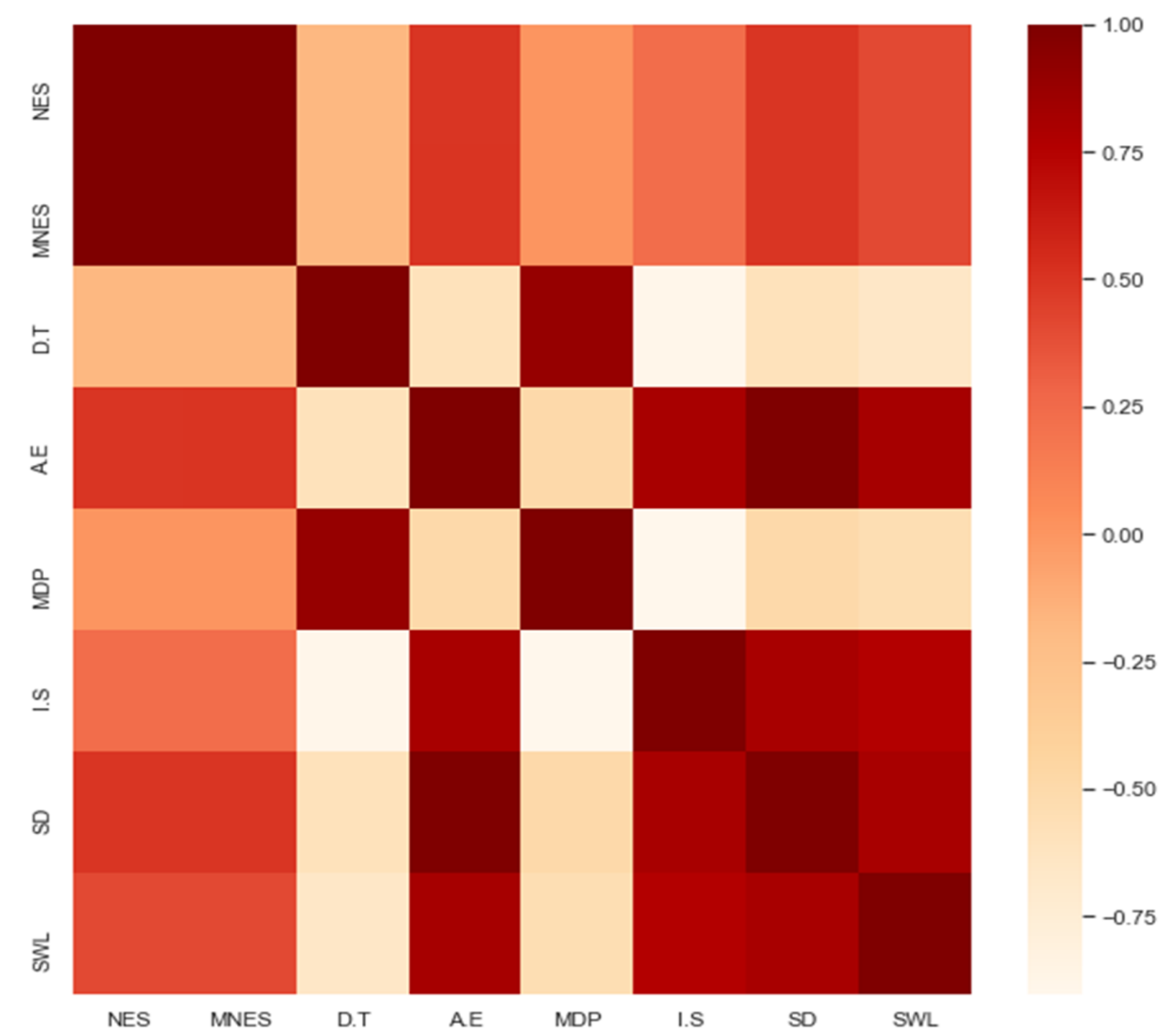

${ }^{*} Y$-axis \& X- axis = Bruchine resistance traits.

Fig. 4. Correlogram heat map on various bruchine resistance traits on blackgram genotypes

than other traits. Based on the $\mathrm{D}^{2}$ study cluster II (TU 68) could be utilized as a donor parent in the development of high yielding black gram (Vigna mungo L. (Hepper)) variety with bruchine resistance. The trait seed weight loss had a significant positive association with a total number of adult emergence, seed damage percentage and index of susceptibility. All these traits had a positive inter-correlation among them. Hence, these traits can be given more importance in formulating the bruchine resistance breeding programme to identify the resistance among the cultivars.

\section{ACKNOWLEDGEMENTS}

The authors acknowledge the help rendered by $\mathrm{Mr}$. Arul Doss, Agricultural Supervisor, National Pulses Research Center (NPRC), Vamban (Tamil Nadu) in the trial.

\section{Conflict of interest}

The authors declare that they have no conflict of interest.

\section{REFERENCES}

1. Anonymous (2019). AICRP MULLaRP- Project coordinator's report: Mungbean and urdbean. Indian Institute of Pulses Res, Kanpur, Pp 35-39.

2. Ceolin, A. C. G., Goncalves-Vidigal, M. C., Vidigal-Filho, P. S. K., Vitschal, M. V., Gonela, A. \& Scapim, C. A. (2007). Genetic divergence of Phaseolus vulgaris $L$. using morpho-agronomic traits by multivariate analysis. Hereditas. 144: 1-9. https://doi.org/10.1111/j.2006.0018-0661.0 1943.x

3. Dongre, T. K., Pawar, S. E., Thakre, R. G. \& Harwalker, M. R. (1996). Identification of resistance sources to cowpea weevil in Vigna $s p$. and its inheritance of their resistance in blackgram. J. Stored Prod. Res., 32: 201-204. https://doi.org/10.1016/S0022-474X(96)00028-8 
4. Ghosh, S., Roy, A. \& Kundagrami, S. (2019). Diversity analysis of mungbean [Vigna radiata(L.) Wilczek] genotypes for bruchine resistance. Indian J. Agric. Res., 53 (3), 309-314. http://dx.doi.org/10.18805/IJARe.A-5155.

5. Indhu, S. M., Manivannan, N., Mahalingam, A. \& Kavitha, Z. (2018). Variability for bruchine resistance in blackgram (Vigna mungo (L.) Hepper). Electron J. PI. Breed., 9 (2), 786 - 789. DOI: 10.5958/0975928X.2018.00097.2.

6. Johnson, H. W., Robinson, H. F. \& Comstock, R. E. (1955). Estimates of genetic and environmental variability in soybean. Agron. J., 47, 314-318.

7. Manivannan, N. (2014). TNAUSTAT- Statistical package. Retrieved from https://sites.google.com/site/ tnaustat.

8. Mohammad, S., Bacha, S., Arshad, M., Din, R. \& Ghafoor, A. (2009). Genetic diversity for determining yield potential and selection criteria in genetic resources. Pakistan Journal of Botany. 41: 298 - 793.

9. Perera, U. I. P., Chandika, K. K. J. \& Ratnasekera, D. (2017). Genetic variation, character association and evaluation of mungbean genotypes for agronomic and yield components. J. Natn. Sci. Foundation Sri Lanka. 45 (4), 347 - 353. http://doi.org/10.4038/jnsfsr.v4 $5 \mathrm{i} 4.8228$.

10. Ponnusamy, D., Pratap, A., Singh, K. S. \& Gupta, S. (2014). Evaluation of Screening Methods for Bruchine Beetle (Callosobruchus chinensis) resistance in Greengram (Vigna radiata) and Blackgram (Vigna mungo) genotypes and influence of seed physical characteristics on its infestation. Vegetos, 27 (1), 60-67. DOI: 10.5958/ j.2229-4473.27.1.011.

11. Reddy, A. K., ShanthiPriya, M., Reddy, D. M. \& Reddy, B. R. (2018). Genetic Divergence Studies in Black gram (Vigna mungo (L.) Hepper), Int. J. Pure App. Biosci. 6(5), 232-237.

12. Sharifi, P., Astereki, H. \& Pouresmael, M. (2018). Evaluation of variations in chickpea (Cicer arietinum L.) yield and yield components by multivariate technique. Annals of Agrarian Sci., 30, 1-7. https://doi.org/10.1016/j.aasci.20 18.02.003.

13. Somta, P., Ammaranan, C., Peter, A. C. O. \& Srinives, P. (2007). Inheritance of seed resistance to bruchines in cultivated mungbean (Vigna radiata, L. Wilczek). Euphytica. 155, 47-55. https://doi.org/10.1007/s10681-006-9299-9

14. Soundararajan, R., Geetha, S., Chitra, N. \& Dinakaran, D. (2013). Resistance in Vigna mungo var. silvestris against Bruchines, Callosobruchus maculatus (F.). Annals Pl. Prot. Sci., 21(2), 279-282.

15. Swamy, S. G., Mahalakshmi, M, S. \& Souframanien, J. (2016). Evaluation of certain blackgram varieties for resistance to pulse bruchine, Callosobruchus maculatus (F.). J. Res. ANGRAU. 44, 8-13.

16. Swella, G. B. \& Mushobozy, M. K. (2009). Comparative susceptibility of different legume seeds to infestation by cowpea bruchine Callosobruchus maculatus (F.) (Coleoptera: Chrysomelidae). Pl. Prot. Sci., 45 (1), 19-24.

17. Upadhyaya, H. D., Ortiz, R., Bramel, P. J. \& Singh, S. (2002). Phenotypic diversity for morphological and agronomic characteristics in chickpea core collection. Euphytica, 123, 333-342. https://doi.org/10.1023/A:101508 841 7487. 